\title{
Snail modulates JNK-mediated cell death in Drosophila
}

Chenxi Wu ${ }^{1,2}$, Zhuojie $\mathrm{Li}^{1}$, Xiang Ding ${ }^{1}$, Xiaowei Guo', Ying Sun ${ }^{1}$, Xingjun Wang ${ }^{1,4}$, Yujia Hu $\mathbb{1}^{1,5}$, Tongtong Li ${ }^{2}$, Xiaojin $\mathrm{La}^{2}$, Jianing $\mathrm{Li}^{2}$, Ji-an $\mathrm{Li}^{2}$, Wenzhe $\mathrm{Li}^{1}$ and Lei Xue $\mathbb{B}^{1,3}$

\begin{abstract}
Cell death plays a pivotal role in animal development and tissue homeostasis. Dysregulation of this process is associated with a wide variety of human diseases, including developmental and immunological disorders, neurodegenerative diseases and tumors. While the fundamental role of JNK pathway in cell death has been extensively studied, its down-stream regulators and the underlying mechanisms remain largely elusive. From a Drosophila genetic screen, we identified Snail (Sna), a Zinc-finger transcription factor, as a novel modulator of ectopic Egr-induced JNK-mediated cell death. In addition, sna is essential for the physiological function of JNK signaling in development. Our genetic epistasis data suggest that Sna acts downstream of JNK to promote cell death. Mechanistically, JNK signaling triggers dFoxO-dependent transcriptional activation of sna. Thus, our findings not only reveal a novel function and the underlying mechanism of Sna in modulating JNK-mediated cell death, but also provide a potential drug target and therapeutic strategies for JNK signaling-related diseases.
\end{abstract}

\section{Introduction}

The Sna superfamily of transcription factors has been implicated in a broad spectrum of important biological functions, including mesoderm formation, epithelial-mesenchymal transition (EMT), tumor recurrence, immune regulation, neural differentiation, left-right identity, cell fate, and survival decisions ${ }^{1-4}$. Most of the Sna family members share a similar organization, with a evolutionarily conserved C-terminal domain that contains four-six $\mathrm{C}_{2} \mathrm{H}_{2}$-type Zinc-fingers for DNA binding, whereas the $\mathrm{N}$ terminus with a SNAG (Snail/Gfi) domain harbors the repressor activity ${ }^{1}$. As the first member of the Sna family, sna was identified as a critical regulator of mesoderm development in Drosophila

\footnotetext{
Correspondence: Lei Xue (lei.xue@tongji.edu.cn)

'Institute of Intervention Vessel, Shanghai 10th People's Hospital, Shanghai Key Laboratory of Signaling and Disease Research, School of Life Sciences and Technology, Tongji University, 1239 Siping Road, Shanghai 200092, China ${ }^{2}$ College of Traditional Chinese Medicine, North China University of Science and Technology, 21 Bohai Road, Tangshan 063210, China

Full list of author information is available at the end of the article.

These authors contributed equally: Chenxi Wu, Zhuojie Li

Edited by E. Baehrecke
}

melanogaster $^{5-7}$. Although lacking the SNAG domain, Drosophila Sna has a consensus Pro-X-Asp-Leu-Ser-XLys (P-DLS-K) motif and executes its repressive function via interacting with a co-repressor, carboxy-terminalbinding protein $(\mathrm{CtBP})^{8,9}$. As such, the fruit fly offers opportunities to investigate the physiological functions of Sna during development.

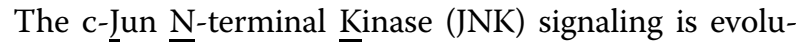
tionarily conserved from fruit fly to human, and plays crucial roles in regulating a wide range of cellular activities including proliferation, differentiation and migration, especially cell death ${ }^{10,11}$. This pathway can be triggered by various extrinsic and intrinsic signals, and is mediated through a mitogen-activated protein kinase (MAPK) cascade $^{12}$. In Drosophila, the tumor necrosis factor (TNF) ortholog Eiger (Egr) binds to its receptor Grindelwald (Grnd), which in turn activates the conserved JNK cascade including dTAK1 (JNKK kinase), Hemipterous (Hep, the JNK kinase) and Basket (Bsk, the Drosophila JNK) ${ }^{13-17}$. Upon activation, Bsk phosphorylates and activates downstream transcription factors including the forkhead box $\mathrm{O}$ (FoxO), which modulates UV-induced Bsk-

\section{(c) The Author(s) 2019}

(c) (i) Open Access This article is licensed under a Creative Commons Attribution 4.0 International License, which permits use, sharing, adaptation, distribution and reproduction cc) in any medium or format, as long as you give appropriate credit to the original author(s) and the source, provide a link to the Creative Commons license, and indicate if changes were made. The images or other third party material in this article are included in the article's Creative Commons license, unless indicated otherwise in a credit line to the material. If material is not included in the article's Creative Commons license and your intended use is not permitted by statutory regulation or exceeds the permitted use, you will need to obtain permission directly from the copyright holder. To view a copy of this license, visit http://creativecommons.org/licenses/by/4.0/. 
mediated cell death by directly up-regulating the proapoptotic gene hid expression ${ }^{18,19}$. Although tremendous effort has been made to complete the regulatory network centered on Egr-Bsk pathway in cell death ${ }^{20-24}$, the downstream regulators and the underlying mechanisms remain poorly understood.

In this study, we used Drosophila melanogaster as an excellent in vivo system and identified Sna as a novel modulator of JNK pathway. First, our genetic analysis indicates that Sna functions downstream of JNK to regulate ectopically activated JNK-induced cell death in eye and wing development. We further show that loss of sna can block physiologically activated JNK signalinginduced cell death, and that Sna is necessary and sufficient for JNK-induced puc expression. Moreover, we demonstrate that Sna modulates dFoxO-triggered cell death. Finally, we provide evidence that gain of JNK signaling promotes $\mathrm{dFoxO}$-dependent sna transcription. In conclusion, these findings reveal a previously unrecognized function of Sna in JNK signaling-mediated cell death, in addition to its well-accepted roles in development and EMT.

\section{Results}

Depletion of sna suppresses ectopic Egr-induced cell death in development

Ectopic expression of the TNF ortholog Egr in Drosophila eyes driven by GMR-GAL4 (GMR > Egr) produces a small eye phenotype in the adult stage (Fig. 1b, c) ${ }^{14,15}$. and triggers apoptotic cell death posterior to the morphogenetic furrow (MF) in third instar eye discs, as revealed by acridine orange (AO) staining that detects dying cells (Fig. 2a, b) ${ }^{25}$, and anti-CDcp-1 antibody staining that specifically recognizes the cleaved effector caspase Dcp-1 (Supplementary Fig. 1a, b) ${ }^{26}$. As the fly eye is also the most accepted organ of the nervous system ${ }^{27}$, to quantify the extent of Egr-induced neuronal loss, we employed the $U A S$-mCD8-RFP (a fusion protein between mouse lymphocyte marker CD8 and the fluorescence protein) reporter system ${ }^{28}$, and found that ectopic Egr resulted in remarkable loss of the photoreceptor neurons in Drosophila adult eyes (Fig. 1j, k, m).

To identify additional factors that regulate Egr-induced cell death, we performed a genetic screen for dominant modifiers of the GMR > Egr-induced small eye phenotype using the Bloomington Drosophila Stock Center Deficiency $\mathrm{kit}^{21-24,29}$. One of the suppressors was mapped cytologically within 35D2-35D4, a region uncovered by three overlapping deficiencies $D f(2 L) E D 1050, D f(2 L)$ ED1054, and Df(2L)Exel7063 (Fig. 1a). Amalgamating such deficiency into GMR > Egr background significantly suppressed the reduced eye size (Fig. 1d-f). This region contains nine genes including snail (sna) (Fig. 1a), the Drosophila ortholog of Sna superfamily ${ }^{1}$, which encodes a $\mathrm{C}_{2} \mathrm{H}_{2}$ zinc finger transcription factor involved in embryonic mesoderm development, EMT and asymmetric cell division ${ }^{5,30-34}$. Intriguingly, the $G M R>$ Egr eye phenotype was suppressed to a similar extent in heterozygous sna mutants (Fig. 1g), suggesting loss of sna is responsible for the suppressive effect of the deficiencies. Consistently, GMR > Egr triggered small eye phenotype, cell death, and photoreceptor loss were notably inhibited by two independent sna RNA interference (RNAi) that target distinct regions of the sna transcript (Fig. 1h, i, l, m; 2d-f; Supplementary Fig. 1d-f). A quantitative reverse transcription polymerase chain reaction (qRT-PCR) assay was performed to verify the knockdown efficiencies of the two sna RNAi lines (Supplementary Fig. 2a). A GFP RNAi was employed as a negative control (Fig. 2c; Supplementary Fig. 1c). Collectively, these results indicate that the transcription factor Sna plays an essential role in ectopic Egr-triggered cell death during eye development.

In Drosophila, sna, esgcargot (esg) and worniu (wor) are considered to be functionally redundant Snail superfamily members that encode zinc finger transcription factors ${ }^{1,35,36}$. Although esg and wor are located in the vicinity of sna on the chromosome, they are not included in the region uncovered by $D f(2 L)$ Exel7063 (Fig. 1a). We found that $G M R>$ Egr-induced small eye phenotype was not visibly suppressed by depletion of esg or wor (Supplementary Fig. $2 \mathrm{e}-\mathrm{j}$ ), suggesting that esg and wor are not involved in Egr-induced cell death.

To examine whether Sna plays a more general role in cell death, we expressed the pro-apoptotic gene head involution defective (hid) by the GMR-GAL4 driver ${ }^{37}$, and found that $G M R>$ Hid-induced small eye phenotype was not suppressed by knockdown of sna (Supplementary Fig. $2 \mathrm{~b}-\mathrm{d})$, suggesting Sna is specifically involved in Egrtriggered cell death.

Drosophila adult wing represents another excellent model system to investigate cell death in development. Consistent with previous reports, expression of Egr along the anterior/posterior (A/P) compartment boundary driven by patched (ptc)-GAL4 also resulted in apoptotic cell death, revealed by AO staining (Fig. 2c, n) and anti-Cleaved Caspase-3 (CC-3) antibody staining (Supplementary Fig. 1g, h), a read-out of the initiator caspase (Caspase-9-like) DRONC activity ${ }^{38}$, and generated a loss of anterior cross vein (ACV) phenotype (Fig. $2 \mathrm{~g}, \mathrm{~h})^{29,39}$, which was phenocopied by expressing the cell death gene grim $^{23}$. These phenotypes were considerably impeded by RNAi-mediated inactivation of sna (Fig. 2j-l, p-r; Supplementary Fig. 1j-l), but remained unaffected by expression of GFP-IR (Fig. 2i, o; Supplementary Fig. 1i), suggesting that Sna modulates ectopic Egr-promoted cell death in a non-tissue-specific manner. 


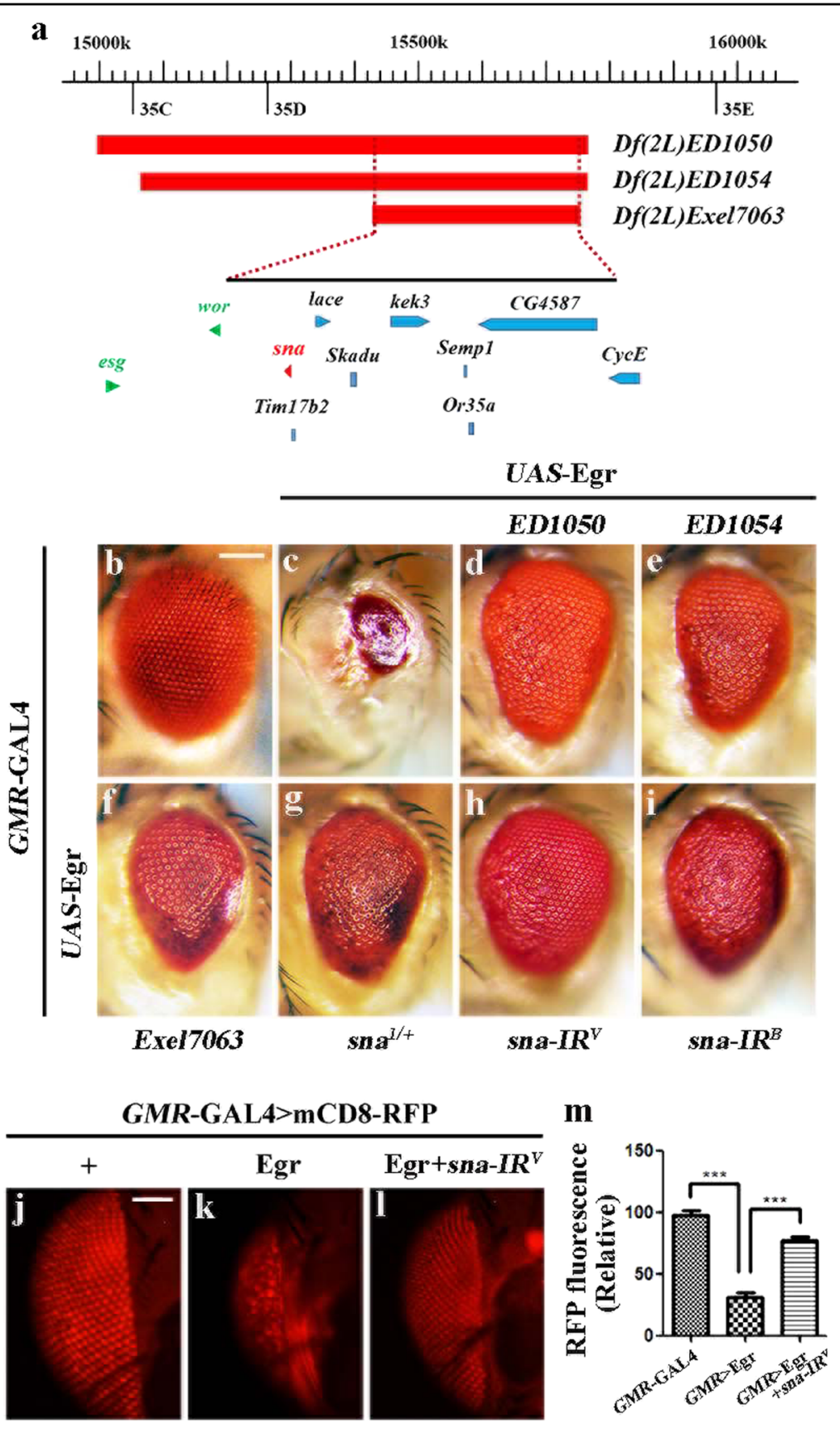

Fig. 1 A genetic screen for dominant modifiers of GMR > Egr-induced eye-ablation phenotype. a A schematic depiction of the genomic region surrounding the sna locus. The three deficiencies Df(2L)ED1050, Df(2L)ED1054, and Df(2L)Exel7063 are indicated. b-i Light micrographs of Drosophila adult eyes are shown. Compared with GMR-GAL4 control $\mathbf{b}$, the GMR> Egr small eye phenotype $\mathbf{c}$ is considerably suppressed by deficiency Df(2L)ED1050 d, Df(2L)ED1054 e, or Df(2L)Exel7063 f that deletes genes including sna, or in heterozygous sna mutant $\mathbf{g}$, or by expressing two independent sna RNAi $\mathbf{h}$ and $\mathbf{i}$. The sample size of Drosophila adult eye is 50. $\mathbf{j}-\mathbf{I}$ Representative fluorescent microscopy images of adult eyes are shown. $\mathbf{m}$ Statistical analysis of fluorescence signals $(n=10)$ shown in figures $\mathbf{j}-\mathbf{I}$. Error bars indicates standard deviation. One-way ANOVA with Bonferroni multiple comparison test was used to compute $P$-values, ${ }^{* * *} P<0.001$. See the electronic supplementary material for detailed genotypes. Scale bar: $100 \mu \mathrm{m}$ in $\mathbf{b}-\mathbf{i}, 50 \mu \mathrm{m}$ in $\mathbf{j}-\mathbf{I}$.

Sna acts downstream of Bsk to modulate cell death

Egr triggers both JNK-dependent and JNKindependent cell death in development ${ }^{14,15,21}$. To determine whether Sna is required for JNK-mediated cell death, we overexpressed dTAK1 (JNKKK) or Hep (JNKK) in the developing eyes. Eye-specific expression of dTAK1 driven by sevenless (sev)-GAL4 or a constitutive activated form of Hep ( $\mathrm{Hep}^{\mathrm{CA}}$ ) driven by GMR-GAL4 


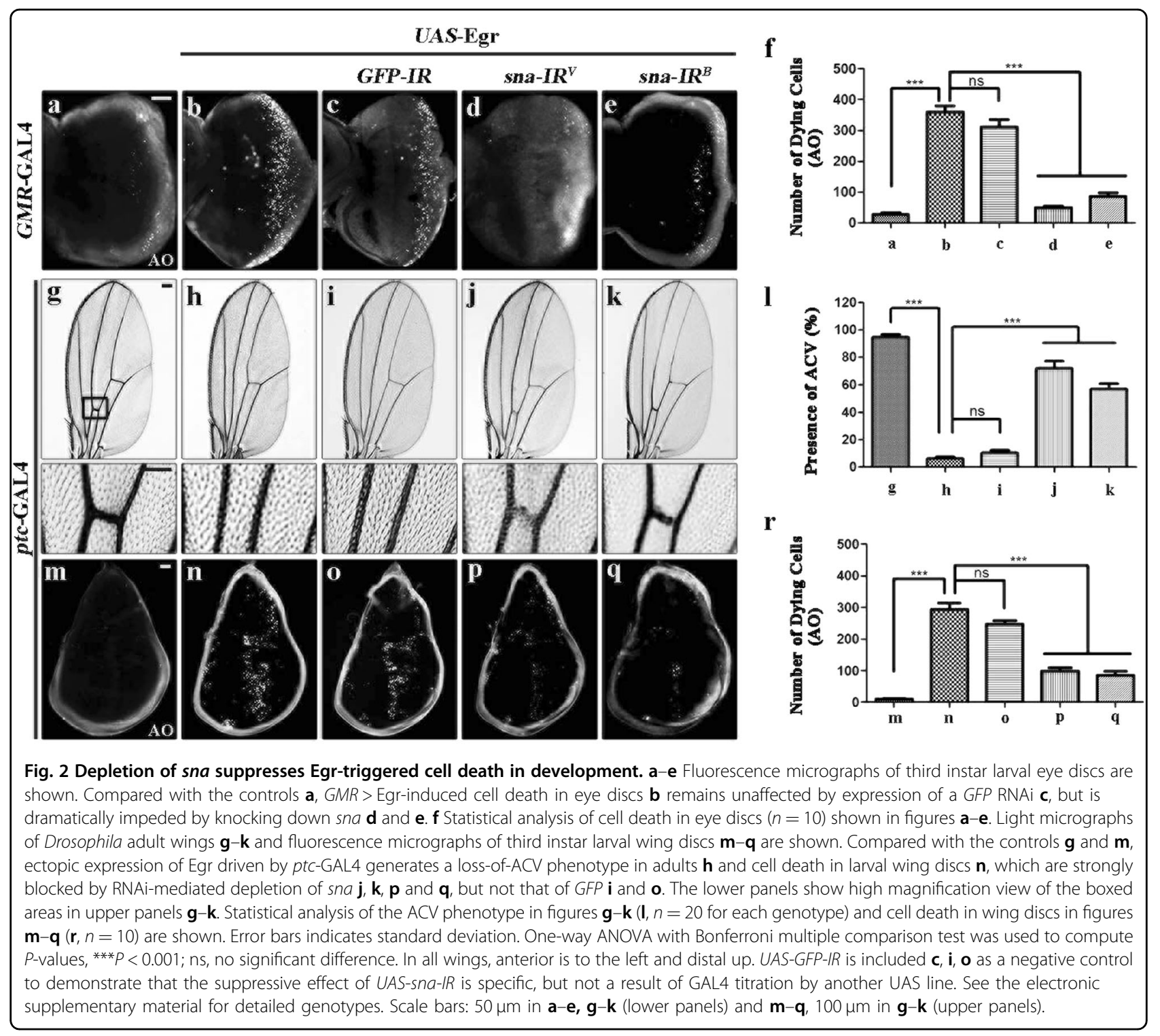

promoted extensive cell death in third instar larval eye discs, which were visualized by terminal deoxynucleotidyl transferase dUTP nick-end labeling (TUNEL) staining that labels both apoptotic and necrotic cells (Supplementary Fig. 3a, f) ${ }^{40,41}$, and generated rough eyes with reduced size (Fig. 3a, e) ${ }^{29,42}$. These phenotypes were suppressed by knockdown of sna (Fig. 3d, h; Supplementary Fig. 3d, e, I, j), but not that of GFP (Fig. 3b, f; Supplementary Fig. 3b, g), while heterozygous $b s k^{l}$ mutants were included as a positive control (Fig. 3c, g; Supplementary Fig. 3c, h). In addition, expression of Puc, a phosphatase that negatively regulates Bsk activity ${ }^{43}$, near fully suppressed the small eye phenotype produced by GMR $>$ Hep $^{\mathrm{CA}}$ (Supplementary Fig. 4). Together, sna is indispensable for Egr-induced Bsk-mediated cell death in eye development.
To investigate whether Sna modulates Bsk-mediated cell death in other cellular contexts, we activated Bsk signaling in the wing or dorsal thorax. Ectopic expression of wild type Hep in the wing pouch driven by Scalloped $(S d)$-GAL4 $\left(S d>\mathrm{Hep}^{\mathrm{WT}}\right)$ promotes broad-scale cell death $^{23}$ that results in severely reduced adult wing blade (Fig. 3i, j), which was significantly suppressed by depleting sna (Fig. 3l, q). Accordantly, ptc $>\mathrm{Hep}^{\mathrm{WT}}$-induced apoptosis in third larval wing discs (Supplementary Fig. 3k, l) and loss-of-ACV phenotype in adult wings (Fig. $3 \mathrm{~m}, \mathrm{n}$ ) were inhibited by expressing a sna RNAi, but not GFP (Fig. 3o, p, r; Supplementary Fig. 3m-o). In addition, we found that expression of Hep driven by pnr-Gal4 ( $p n r>$ $\mathrm{Hep}^{\mathrm{WT}}$ ) triggers cell death in the thora ${ }^{22}$ and produces a small scutellum phenotype, which is partially suppressed by depleting sna, but not GFP (Supplementary Fig. 5). 

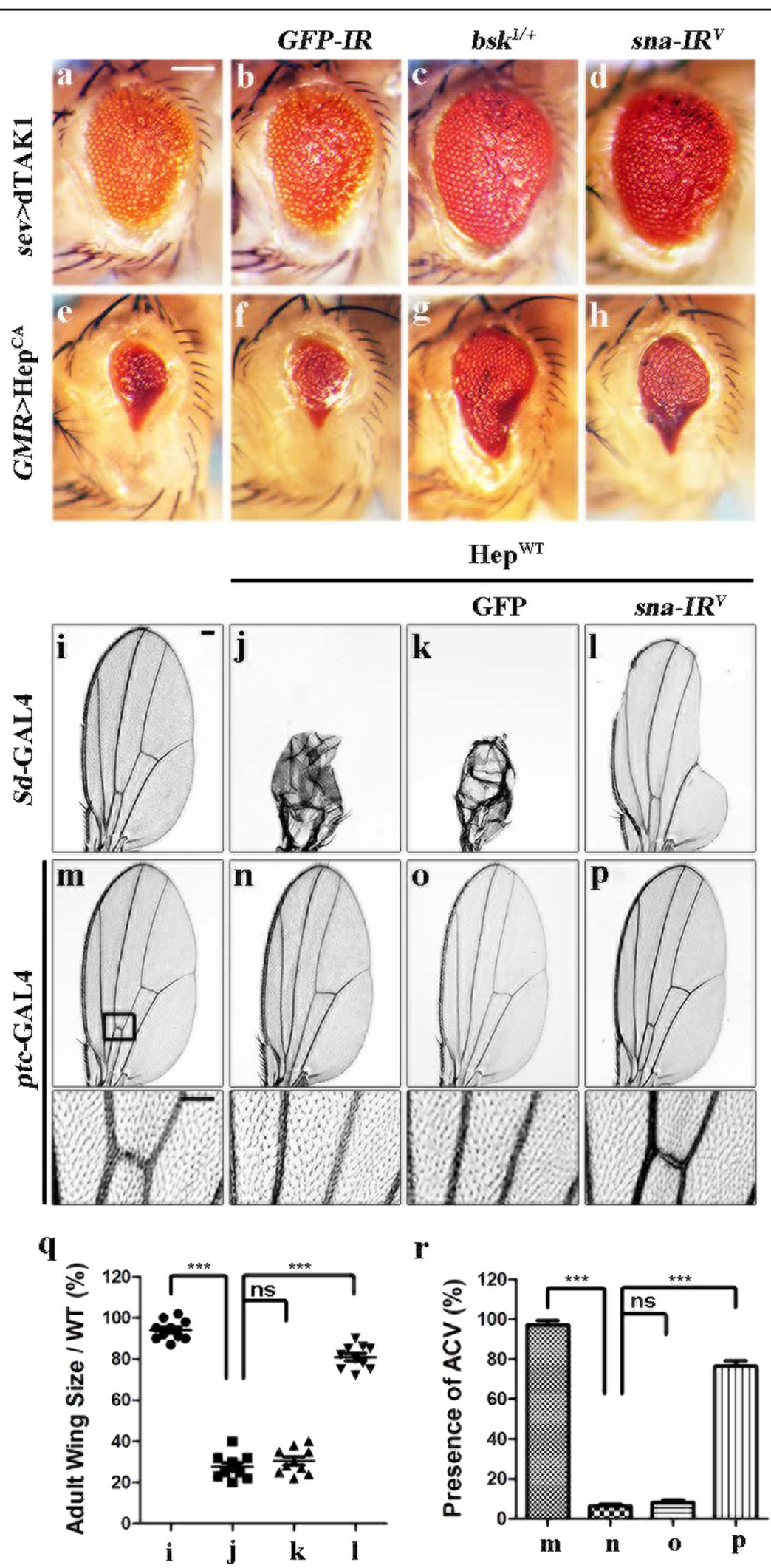

Fig. 3 (See legend on next page.) 
(see figure on previous page)

Fig. 3 Sna acts down-stream of Hep in JNK-mediated cell death. $\mathbf{a}-\mathbf{h}$ Light micrographs showing Drosophila adult eyes. The small and rough eye phenotype resulted from ectopic expression of dTAK1 a or Hep ${ }^{C A}$ e is evidently suppressed by mutating one copy of endogenous bsk $\mathbf{c}$ and $\mathbf{g}$, or knocking-down sna $\mathbf{d}$ and $\mathbf{h}$, but not GFP $\mathbf{b}$ and $\mathbf{f}$, which served as a negative control. i-p Light micrographs of Drosophila adult wings. Compared with the controls $\mathbf{i}$ and $\mathbf{m}$, the wing phenotypes of $S d>\mathrm{Hep}^{\mathrm{WT}} \mathbf{j}$ and $p t c>\mathrm{Hep}^{\mathrm{WT}} \mathbf{n}$ flies are suppressed by expressing a sna-IR $\mathbf{I}$ and $\mathbf{p}$, but not GFP $\mathbf{k}$ and $\mathbf{o}$. In $\mathbf{m}-\mathbf{p}$, the lower panels are high magnification of the boxed areas in upper panels. Statistical analysis of the adult wing size/wild type (WT) $\mathbf{q}(n=10)$ and the ACV phenotype $\mathbf{r}(n=20$ for each genotype) as shown in figures $\mathbf{i}-\mathbf{I}$ and $\mathbf{m}-\mathbf{p}$, respectively. One-way ANOVA with Bonferroni multiple comparison test was used to compute $P$-values, ${ }^{* * *} P<0.001$; ns, no significant difference. In all wings, anterior is to the left and distal up. See the electronic supplementary material for detailed genotypes. Scale bars: $100 \mu \mathrm{m}$ in $\mathbf{a}-\mathbf{I}$ and $\mathbf{m}-\mathbf{p}$ (upper panels), $50 \mu \mathrm{m}$ in $\mathbf{m}-\mathbf{p}$ (lower panels).

Hence, we conclude that Sna regulates JNK-mediated cell death down-stream of Hep in a non-tissue-specific manner.

Moreover, ectopic expression of Bsk under the control of GMR-GAL4 generates a small and rough eye phenotype (Supplementary Fig. 6a, b), which is suppressed by knockdown of sna (Supplementary Fig. 6d), but not expression of GFP (Supplementary Fig. 6c), suggesting that Sna acts down-stream of the JNK cascade to modulate cell death. In addition, ectopic expression of Sna is sufficient to trigger a large scale of cell death in the eye and wing discs (Supplementary Fig. 6e-i, n, s-u), and produce a small eye phenotype in the adulthood (Supplementary Fig. 6j). Consistent with the notion that Sna acts downstream of Bsk, the $G M R>$ Sna-induced cell death and eye phenotype could not be suppressed by expressing Bsk $^{\mathrm{DN}}$, while sna-IR and LacZ served as positive and negative controls, respectively (Supplementary Fig. $6 \mathrm{k}-\mathrm{m}, \mathrm{o}-\mathrm{r})$.

\section{sna is required for the physiological functions of Bsk}

The above data imply that Sna acts as a crucial factor down-stream of Bsk to modulate cell death, yet it remains unknown whether Sna is involved in the physiological role of JNK signaling. To address this question, we knocked down puc, which encodes a JNK phosphatase that negatively regulates $\mathrm{JNK}$ activity ${ }^{43}$, along the A/P compartment boundary of wing discs by ptc-GAL4 (ptc > puc-IR), and observed strong cell death accompanied with increased caspase activity in third-instar larval wing discs (Fig. 4f; Supplementary Fig. 7a), and loss-of-ACV in adult wings (Fig. 4a). All the phenotypes, resulted from the activation of endogenous JNK signaling, were blocked by knockdown of sna, while expression of a dominant negative Bsk $\left(\mathrm{Bsk}^{\mathrm{DN}}\right)$ or LacZ served as a positive or negative control, respectively (Fig. 4bb-e, g-j; Supplementary Fig. 7b-d, i).

It has been reported that loss of cell polarity promotes JNK-mediated cell death in development ${ }^{44-46}$. In agreement with this view, knockdown of the cell polarity gene disc large $(d l g)$ along the $\mathrm{A} / \mathrm{P}$ compartment boundary by ptc-GAL4 ( $p t c>d l g-I R$ ) induces severe cell death (Fig. 4k) and up-regulated caspase activity (Supplementary Fig. 7e) in third instar larval wing discs. Both phenotypes were appreciably blocked by depletion of sna or expression of $\mathrm{Bsk}^{\mathrm{DN}}$, but remained unaffected by the expression of LacZ (Fig. 4l-o; Supplementary Fig. 7f-i). Thus, these data indicate that Sna contributes to the physiological function of Bsk signaling in regulating stress-induced cell death in development.

\section{Sna mediates FoxO-triggered cell death}

The transcription factor forkhead box $\mathrm{O}(\mathrm{FoxO})$ is a known down-stream regulator of Bsk-mediated cell death in response to stress ${ }^{18,19}$. Consistently, we found that $G M R>$ Egr-induced cell death in eye discs and small eye phenotype were significantly impeded in heterozygous dFoxO $\mathrm{O}^{\Delta 94}$ mutants, or by RNAi-mediated knockdown of $d$ FoxO (Fig. $5 \mathrm{a}-\mathrm{c}, \mathrm{g}-\mathrm{i}, \mathrm{m}$ ), suggesting dFoxO also regulates Egr-triggered Bsk-mediated cell death. To investigate the mechanism by which Sna regulates JNK-mediated cell death, we examined the genetic interaction between sna and $d F o x O$. Over-expression of dFoxO driven by GMR-GAL4 triggers intensive cell death in third instar eye discs and produces adult eyes with reduced size (Fig. $5 d, j)^{18,44}$. We found that both phenotypes were dramatically suppressed in heterozygous sna mutants (Fig. 5e, k), and near fully blocked by RNAi-mediated depletion of sna (Fig. 5f, l). Moreover, we found $\mathrm{dFoxO}$ expression in wing development driven by ptc-GAL4, Serrate (Ser)-GAL4, or Scalloped (Sd)GAL4 triggered extensive cell death and generated various wing defects in their corresponding areas, which are efficiently blocked by RNAi-mediated depletion of sna, but not that of GFP (Fig. 5n-w; Supplementary Fig. 8). Taking these data together, we conclude that Sna is required for FoxO-induced cell death in eye and wing development.

Scutoid (Sco) was originally identified as a dominant mutation resulted from a chromosomal transposition that affects sna, and is regarded as a sna gain-of-function allele $^{45}$. Intriguingly, we found that $G M R>d F o x O-$ induced small eye phenotype is notably enhanced in heterozygous Sco mutants (Supplementary Fig. 9), confirming that gain of Sna exacerbates FoxO-induced cell death. 

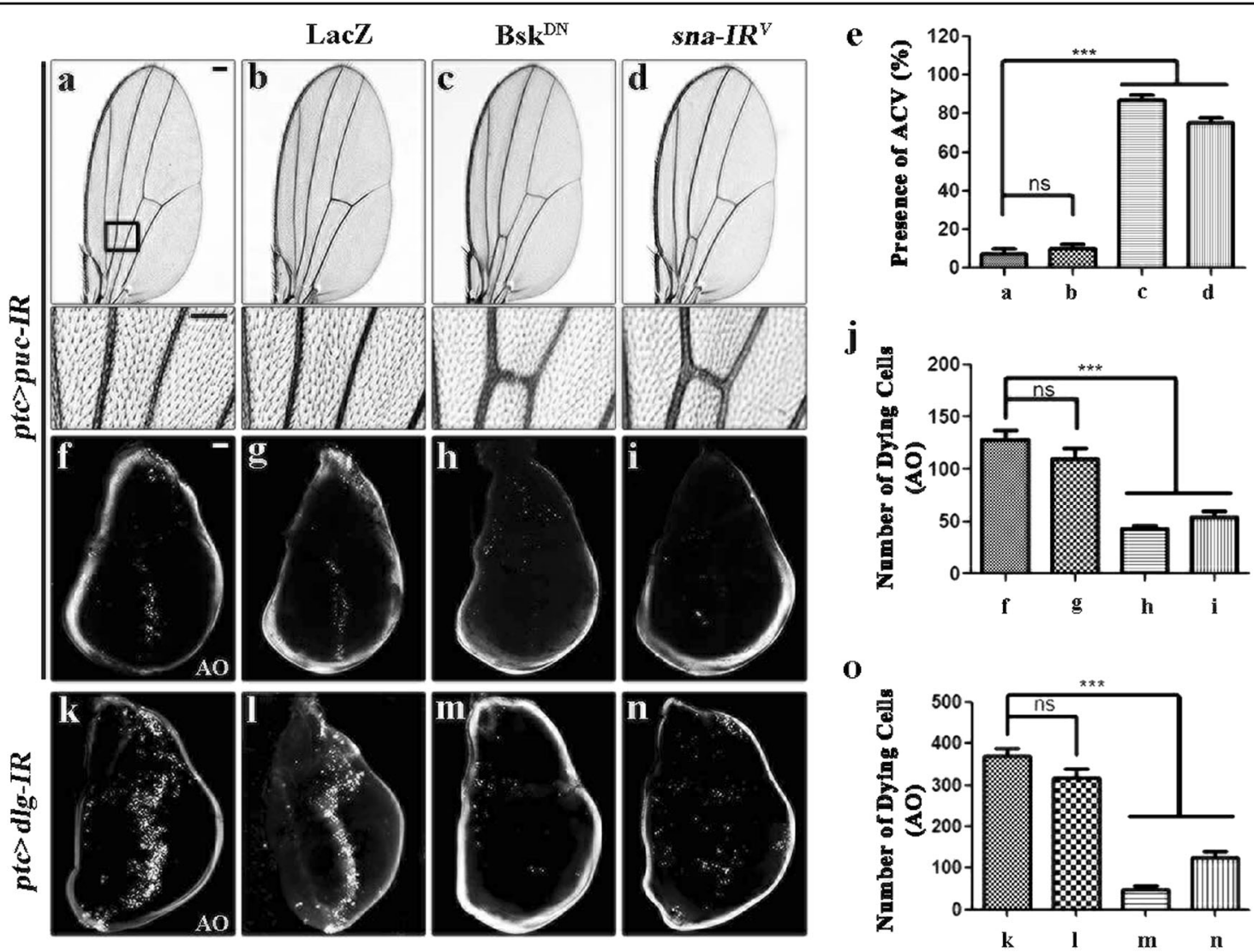

Fig. 4 sna is required for the physiological functions of Bsk. Light micrographs of Drosophila adult wings a-d and fluorescence micrographs of third instar larval wing discs $\mathbf{f}-\mathbf{i}$ and $\mathbf{k}-\mathbf{n}$ are shown. RNAi-mediated down-regulation of puc along the A/P compartment boundary by ptc-GAL4 triggers the loss-of-ACV phenotype in adult wings $\mathbf{a}$, which is resulted from cell death in larval wing discs $\mathbf{f}$. Both phenotypes depend on endogenous Bsk $\mathbf{c}$ and $\mathbf{h}$ and Sna $\mathbf{d}$ and $\mathbf{i}$. The bottom panels show high magnification views of the boxed areas in upper panels $\mathbf{a}-\mathbf{d}$. Knockdown of $d l g$ along the A/P compartment boundary (ptc $>$ dlg-IR) induces Bsk-dependent cell death $\mathbf{k}$ and $\mathbf{m}$, which is significantly blocked by depletion of sna $\mathbf{n}$. LacZ expression is used as a negative control $\mathbf{b}, \mathbf{g}$, and $\mathbf{I}$. $\mathbf{e}, \mathbf{j}$, and $\mathbf{o}$ Statistical analysis of ACV phenotype ( $n=20$ for each genotype) and cell death in wing discs $(n=10)$ as shown in figures $\mathbf{a}-\mathbf{d}, \mathbf{f}-\mathbf{i}$, and $\mathbf{k}-\mathbf{n}$, respectively. Error bars indicates standard deviation. One-way ANOVA with Bonferroni multiple comparison test was used to compute $P$-values, ${ }^{* *} P<0.001$; ns, no significant difference. In all wings, anterior is to the left and distal up. See the electronic supplementary material for detailed genotypes. Scale bars: $100 \mu \mathrm{m}$ in a-d (upper panels), $50 \mu \mathrm{m}$ in a-d (lower panels) and f-n.

\section{JNK signaling activates sna transcription}

The above data suggest that Sna is necessary and sufficient for Bsk-FoxO-signaling-induced cell death in development. Since FoxO encodes a transcription factor, we hypothesized that JNK signaling may activate sna transcription in a FoxO-dependent manner. To test this, we activated JNK signaling in the eye by ectopic expression of Egr or Hep, and checked sna mRNA level by the qRT-PCR assay. In support of our assumption, endogenous sna transcription was evidently up-regulated by ectopic Egr or Hep, and this activation was significantly blocked in heterozygous $d F o x O^{\Delta 94}$ mutants (Fig. 6a), suggesting that JNK-induced sna expression depends on dFoxO. Consistently, the level of sna mRNA was also dramatically up-regulated by ectopic expression of dFoxO, but remained unaffected by that of LacZ (Fig. 6a). Thus, we conclude that JNK signaling triggers FoxO- dependent transcriptional activation of sna, which is necessary and sufficient for JNK-mediated cell death in development.

wingless $(w g)$ is a recognized target of JNK pathway $^{24,46,47}$ and elicits expression of Sna family transcription factors in the peripheral fly eye ${ }^{48}$. To further dissect the function of $\mathrm{Wg}$ in Egr/JNK/FoxO/Sna axis, we first performed the qRT-PCR assay to check $w g$ mRNA level in $G M R>$ Egr eyes. In line with the previous studies, we found that ectopic Egr is sufficient to activate $w g$ transcription (Fig. 6b). Next, we checked whether Wg is required for JNK-mediated sna expression. To this end, we employed two independent $w g$ RNAi and noticed a strong suppressive effects on the elevation of sna mRNA level triggered by Egr (Fig. 6c), but not that induced by FoxO (Fig. 6a), suggesting that Wg may contribute to Egrinduced sna transcription in parallel with FoxO. However, 


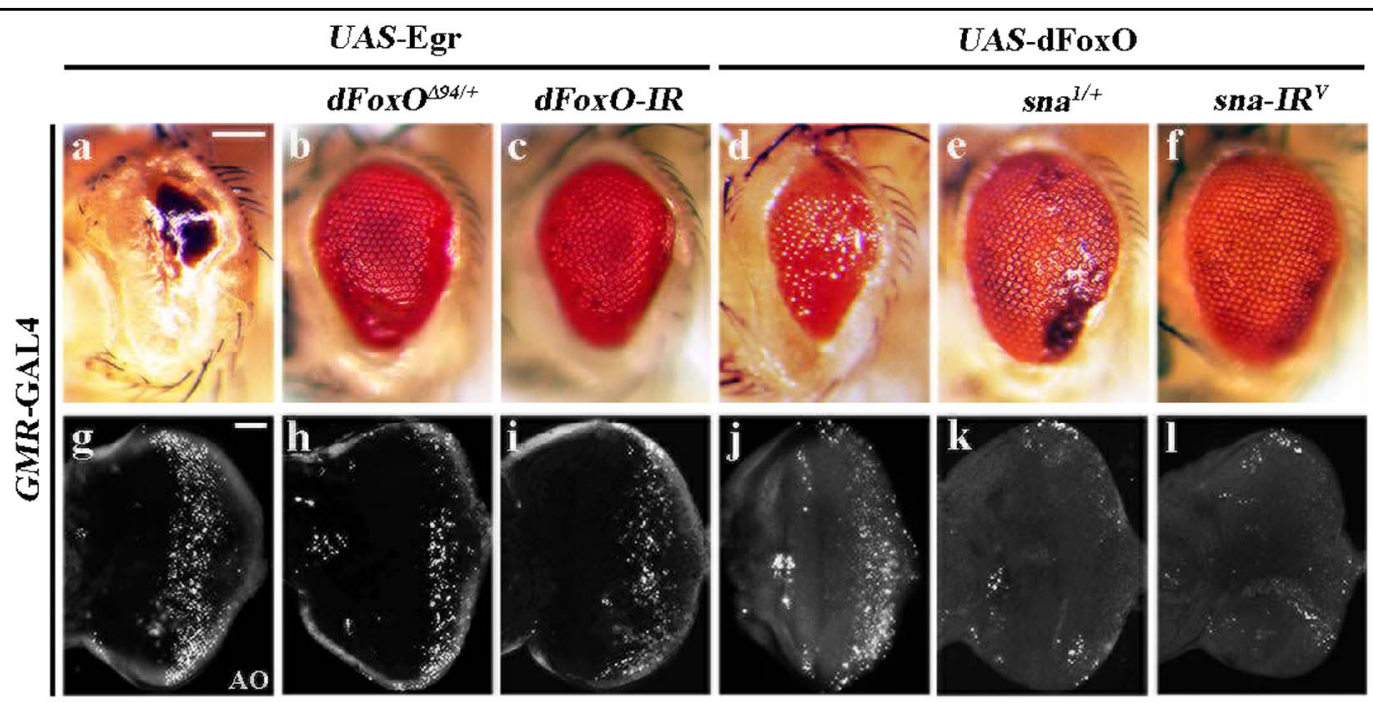

$\mathbf{m}$
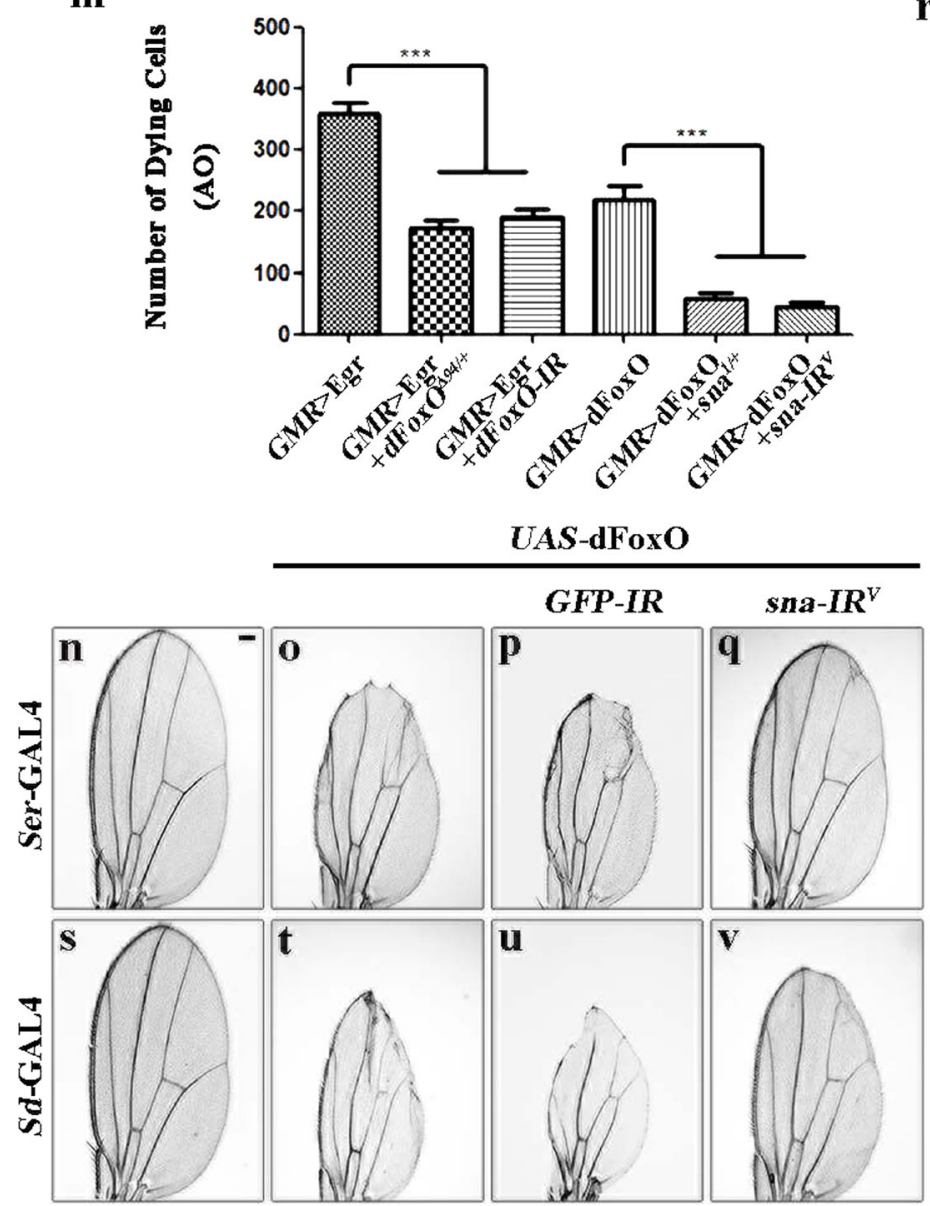

$\mathbf{r}$
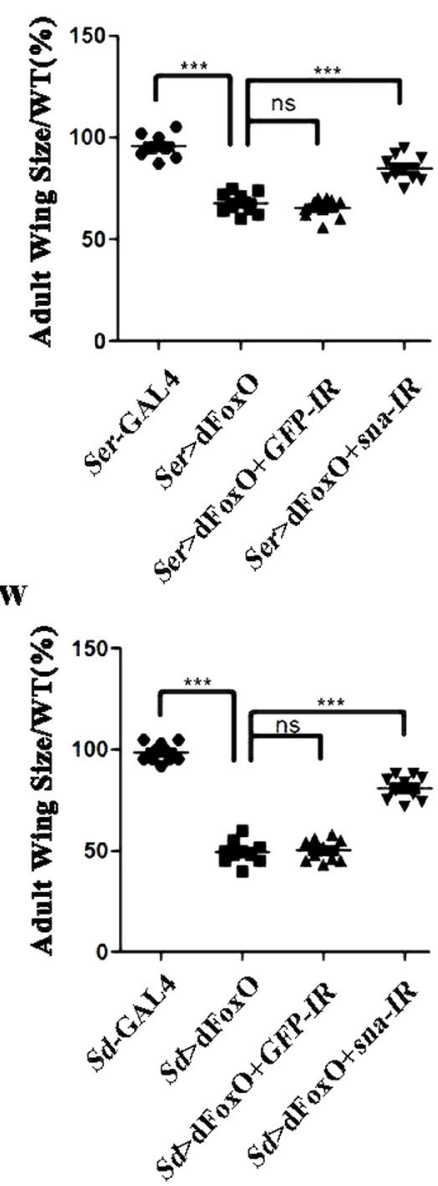

Fig. $\mathbf{5}$ Sna regulates FoxO-mediated cell death. Light micrographs of Drosophila adult eyes $\mathbf{a}-\mathbf{f}$, adult wings $\mathbf{n}-\mathbf{q}$, and $\mathbf{s}-\mathbf{v}$ and fluorescence micrographs of third instar larval eye discs $\mathbf{g}-\mathbf{I}$ are shown. The small eye phenotype and massive cell death, produced by GMR $>$ Egr $\mathbf{a}$ and $\mathbf{g}$, are obviously suppressed in heterozygous $d F o x O^{\triangle 94}$ background $\mathbf{b}$ and $\mathbf{h}$ or by knockdown of $d F o x O \mathbf{c}$ and $\mathbf{i}$. Expression of dFoxO driven by GMR-GAL4 results in reduced eye size and increased cell death in eye discs $\mathbf{d}$ and $\mathbf{j}$, which are suppressed by mutating one copy of endogenous sna $\mathbf{e}$ and $\mathbf{k}$ or RNAi-mediated depletion of sna $\mathbf{f}$ and $\mathbf{I}$. Compared with the controls $\mathbf{n}$ and $\mathbf{s}$, the wing phenotypes of Ser $>\mathrm{dFoxO} \mathbf{o}$ and $S d>d F o x O \mathbf{t}$ flies are partially suppressed by depletion of sna $\mathbf{q}$ and $\mathbf{v}$, but not that of GFP $\mathbf{p}$ and $\mathbf{u}$. In all wings, anterior is to the left and distal up. Statistical analysis of AO staining $\mathbf{m}$, the adult wing size/wild type (WT) $\mathbf{r}$ and $\mathbf{w}$ as shown in figures $\mathbf{g}-\mathbf{I}, \mathbf{n}-\mathbf{q}$, and $\mathbf{s}-\mathbf{v}$, respectively $(n=10)$. One-way ANOVA with Bonferroni multiple comparison test was used to compute $P$-values, ${ }^{* * *} P<0.001$; ns, no significant difference. See the electronic supplementary material for detailed genotypes. Scale bar: $100 \mu \mathrm{m}$ in $\mathbf{a}-\mathbf{f}, \mathbf{n}-\mathbf{q}$ and $\mathbf{s}-\mathbf{v}, 50 \mu \mathrm{m}$ in $\mathbf{g}-\mathbf{I}$. 


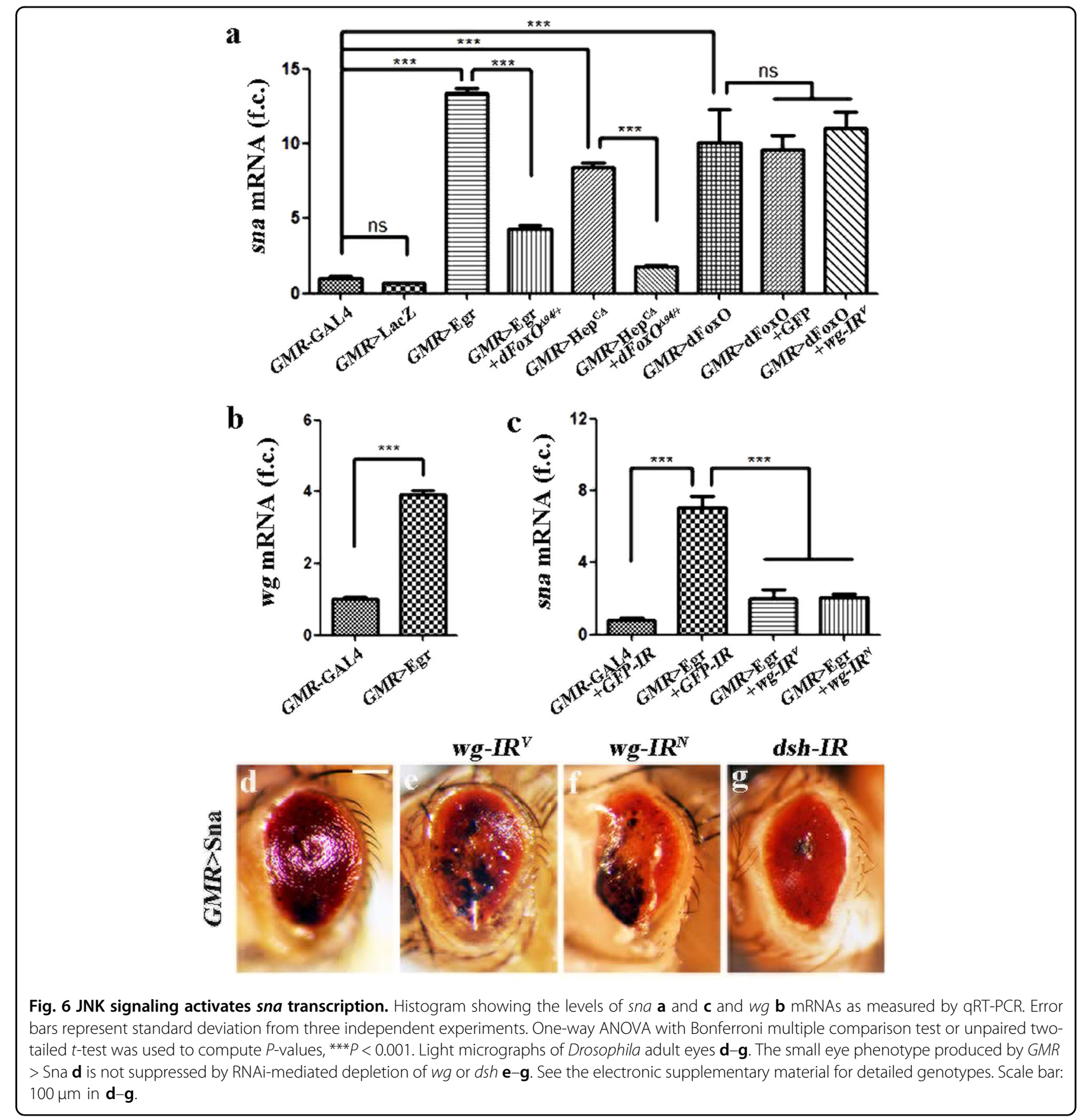

the $G M R>$ Sna-induced small eye phenotype could not be blocked by knockdown of $w g$ or disheveled (dsh) (Fig. 6d-g), which encodes a scaffold protein as the Wg transducer ${ }^{49}$. Thus, we confirmed that $w g$ is involved in Egr/JNK-mediated sna transcription, but not required for Sna-promoted cell death.

\section{Sna induces puc activation in vivo}

The above data suggest that Sna is a crucial downstream factor mediating JNK-dependent cell death. Next, to check if Sna could activate puc transcription in vivo, we examined the expression of puc-LacZ reporter by executing an X-Gal-staining assay ${ }^{42}$. Compared with the $S d$-GAL4 control, expression of Hep ${ }^{\mathrm{WT}}$ or Sna strongly induces up-regulation of puc-LacZ (Fig. 7a-c). Furthermore, the activation of puc in wing pouch along the $\mathrm{A} / \mathrm{P}$ boundary triggered by $p t c>\mathrm{Hep}^{\mathrm{WT}}$ could be moderately impeded by mutation in sna (Fig. $7 \mathrm{~d}-\mathrm{f}$ ), suggesting Sna is both necessary and sufficient for JNK-mediated puc expression. Consistent with the genetic data that Sna acts 


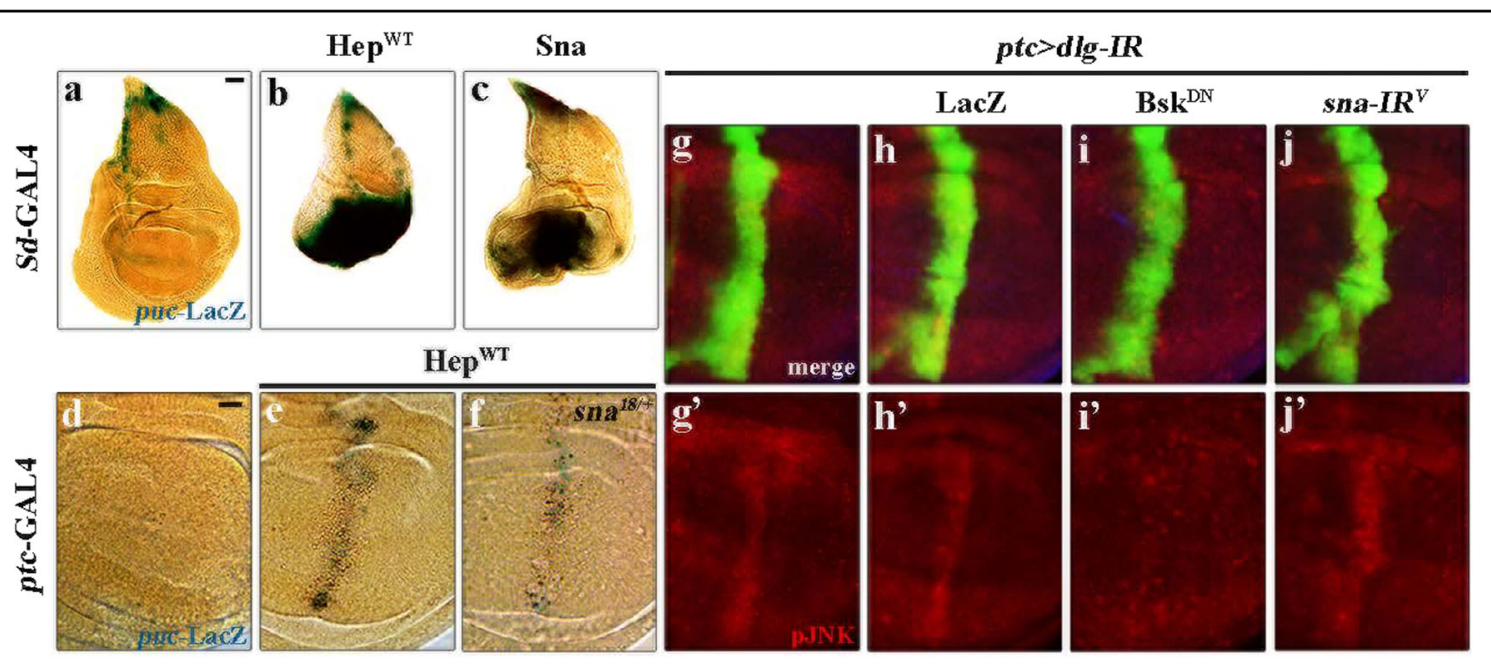

Fig. 7 sna activates puc transcription in vivo. a-f Light micrographs showing X-Gal staining of a puc-LacZ reporter in wing discs. Compared with the control $\mathbf{a}$, overexpression of Hep ${ }^{W T}$ or Sna in the wing pouch notably upregulated puc transcription $\mathbf{b}$ and $\mathbf{c}$. Compared with ptc-GAL4 $\mathbf{d}$, the increased puc-LacZ expression triggered by Hep ${ }^{W T}$ along the A/P compartment boundary $\mathbf{e}$ is partially impeded in heterozygous sna mutant f. $\mathbf{g}$-j Fluorescence micrographs of Drosophila third instar larval wing discs are shown. The elevated JNK phosphorylation induced by knockdown of dlg $\mathbf{g}$ and $\mathbf{g}^{\prime}$ remains unaffected by RNAi-mediated depletion of sna $\mathbf{j}$ and $\mathbf{j}^{\prime}$. LacZ and Bsk ${ }^{\mathrm{DN}}$ expressions are used here as negative and positive controls, respectively $\mathbf{h}, \mathbf{h}^{\prime}, \mathbf{i}$ and $\mathbf{i}^{\prime}$. See the electronic supplementary material for detailed genotypes. Scale bar: $50 \mu \mathrm{m}$ in $\mathbf{a}-\mathbf{c}, 20 \mu \mathrm{m}$ in $\mathbf{d}-\mathbf{j}$.

downstream of Bsk, depletion-of-dlg-triggered JNK phosphorylation was inhibited by expression of Bsk ${ }^{\mathrm{DN}}$, but not that of a sna RNAi or LacZ (Fig. $7 \mathrm{~g}-\mathrm{j})$.

\section{Discussion}

With the sophisticated genetic tools and conserved cell death machinery, Drosophila has been widely considered as an excellent model organism to unravel novel regulators of the cell death program during the last two decades $^{50-52}$. In this study, we took advantage of the fly genetics and identified Sna as a novel regulator of Egrinduced cell death from a deficiency screen. Our genetic epistasis analysis established Sna as a crucial downstream mediator of the Egr-JNK-FoxO signaling in cell death. Mechanistically, Egr-JNK pathway activates sna transcription via FoxO. Previous work has reported that Wg signaling elicits expression of Sna family transcription factors in eye peripheral retinal apoptosis ${ }^{48}$. In addition, Zhang et al. reported that $w g$ is required for GMR $>$ Egrinduced cell death, and that $w g$ expression is activated by Jun/Fos-mediated Egr-JNK signaling ${ }^{24}$. Thus, we are curious if $\mathrm{Wg}$ is required for JNK-mediated sna transcription. Our data demonstrate that Wg also contributes to Egr-induced sna transcription, but is not involved in the FoxO-promoted sna expression. These data suggest that the Egr-JNK signaling activates sna transcription by at least two independent mechanisms: FoxO and Jun/FosWg. Moreover, we found Sna is sufficient to activate $p u c$ transcription, implying JNK activates puc expression via multiple means. Intriguingly, different from the previously reported functional redundancy in development ${ }^{1,36}$, the other two Drosophila Sna family proteins Esg and Wor are not involved in Egr-induced JNK-mediated cell death. Given the evolutionary conserved role of Sna and JNK, the data presented in this study may suggest a novel function of mammalian Sna family proteins in JNK-mediated cell death, in addition to its well-accepted roles in EMT, cell fate decision and survival.

\section{Materials and methods}

\section{Fly strains}

Flies were kept on a cornmeal and agar medium at $25^{\circ} \mathrm{C}$ according to standard protocols. Drosophila strains used include: $s n a^{1}$ (25127), sna ${ }^{18}$ (3299), UAS-sna-IR ${ }^{B}$ (28679), UAS-mGFP (32197), bsk ${ }^{1}$ (3088), UAS-Bsk, UAS-dFoxO (9575), Ser-GAL4 (6791), Sco/CyO (2555), UAS-mCD8RFP (32219), UAS-dsh-IR (31306), wor ${ }^{1}(3155)$, wor $^{4}$ (25170) and the deficiency kit were obtained from Bloomington Drosophila stock center. UAS-sna-IRV (6263), UAS-puc-IR (3018), UAS-dlg-IR (41136), and UAS-wg-IR (13352) were obtained from Vienna Drosophila RNAi center. UAS-wg-IR ${ }^{N}$ (4889R-4), UAS-esg-IR ${ }^{N-1}$ (3758R-1), and UAS-esg-IR ${ }^{N-2}(3758 \mathrm{R}-5)$ were received from Fly Stocks of National Institute of Genetics (NIG-FLY). UASGFP-IR (0355) and UAS-wor-IR (GL00186) were obtained from TsingHua Fly Center. GMR-GAL4 $4^{53}$; $S d$-GAL4 and ptc-GAL4 $4^{39}$; UAS-Egr, UAS-Egr ${ }^{\mathrm{W}}$, and UAS-Hid ${ }^{14}$; UASBsk $^{\mathrm{DN}}$, UAS-Puc, and $p u c^{E 6942}$; sev-GAL4, UAS-dTAK1, $U A S$-Hep ${ }^{\mathrm{CA}}, U A S-\mathrm{Hep}^{\mathrm{WT}}$, UAS-LacZ, pnr-GAL4, and UAS-GFP ${ }^{22,29,54} ; d F o x O^{494}$ and UAS-dFoxO-IR ${ }^{39}$ were previously described. UAS-Sna ${ }^{74 b}$ fly was a kind gift of J. Kumar. For all fly cross experiments, healthy unmated 
male and female parents were randomly assigned to different groups. Double-blinded method was employed during the experiments.

\section{AO staining}

Eye and wing discs were dissected from third instar larvae in PBST and incubated in $1 \times 10^{-5} \mathrm{M}$ AO for $5 \mathrm{~min}$ at room temperature prior to imaging as described ${ }^{21}$.

\section{TUNEL staining}

The wing and eye discs were dissected from wandering third-instar larvae in PBS. Discs were fixed in $4 \%$ paraformaldehyde for $30 \mathrm{~min}$ at room temperature and washed with PBS-Tx $(0.3 \%$ Triton100) three times for $30 \mathrm{~min}$. TUNEL staining was performed using the Fluorescein Cell Death Kit produced by Boster Company.

\section{X-Gal staining}

Wing discs were dissected from third instar larvae in PBST $(1 \times$ PBS pH 7.0, 0.1\% Triton X-100) and stained for ß-galactosidase activity as described ${ }^{21}$.

\section{qRT-PCR}

TRIzol (Invitrogen) was used to isolate total RNA from 10 wing imaginal discs dissected from third instar larvae or 30 adult heads collected from freshly eclosed flies of indicated genotypes, and qRT-PCR was performed as previously described ${ }^{55}$ using following primers:

For $r p 49$ Sense: $5^{\prime}$-TACAGGCCCAAGATCGTGAA-3' Antisense: 5'-TCTCCTTGCGCTTCTTGGA-3'

For sna Sense: 5'-ATGGCCGCCAACTACAAAAG-3' Antisense: 5'-GCAAACTGTGAGTCCTTGGTC-3' For $w g$ Sense: 5'-CCAAGTCGAGGGCAAACAGAA-3' Antisense: 5'-TGGATCGCTGGGTCCATGTA-3'.

\section{Immunohistochemistry}

Imaginal wing discs dissected from third instar larvae were collected in cold PBS and fixed in $4 \%$ paraformaldehyde. After proper washes, the wing discs were blocked in $10 \%$ horse serum, and stained with antibodies. The following antibodies were used: rabbit anti-Cleaved Dcp-1 (1:100, Cell Signaling Technology, Cat. \#9578), rabbit anti-Cleaved Caspase-3 (1:200, Cell Signaling Technology, Cat. \#9661), and rabbit anti-phospho-JNK (1:200, Calbiochem, Cat. \#559309). Secondary antibody was goat anti-Rabbit-Cyanine3 (1:1000, Life technologies, Cat. \#A10520). Vectashield mounting media (Vector Laboratories, Cat. \#H-1500) was used for mounting.

\section{Data and statistics}

All data were verified in at least three independent experiments. Results are presented as bar graphs or scatter plots created using GraphPad Prism 6.0. A combination of unpaired two-tailed $t$-test and one-way
ANOVA with Bonferroni's multiple comparison test was used to calculate statistical significance. Center values' as mean. Error bars indicates standard deviation. $P$ value $<$ 0.05 was considered significant. ns is not significant, $P \geq$ 0.05 ; * is $P<0.05$; ${ }^{* *}$ is $P<0.01$; *** is $P<0.001$. $P$ values are included in the relevant figure legends.

\begin{abstract}
Acknowledgements
We thank Bloomington, VDRC, NIG, TsingHua Fly Centers, and the Core Facility of Drosophila Resource and Technology, Shanghai Institute of Biochemistry and Cell Biology, Chinese Academy of Sciences for fly stocks and members of Xue lab for discussion and critical comments. This work was supported by National Natural Science Foundation of China $(31571516,31771595)$, and Shanghai Committee of Science and Technology (09DZ2260100) to Lei Xue, and National Natural Science Foundation of China (31701244), Natural Science Fund of Hebei Province of China (C2018209119), Scientific and Technological Research Project of Higher Education of Hebei Province (BJ2019040), and Doctoral Scientific Research Foundation of North China University of Science and Technology (BS2017063) to Chenxi Wu.
\end{abstract}

\section{Author details}

'Institute of Intervention Vessel, Shanghai 10th People's Hospital, Shanghai Key Laboratory of Signaling and Disease Research, School of Life Sciences and Technology, Tongji University, 1239 Siping Road, Shanghai 200092, China. ${ }^{2}$ College of Traditional Chinese Medicine, North China University of Science and Technology, 21 Bohai Road, Tangshan 063210, China. ${ }^{3}$ Center of Intervention Radiology, Zhuhai People's Hospital, Zhuhai 519000, China. ${ }^{4}$ Present address: Department of Neuroscience, Scripps Research Institute, 130 Scripps Way, Jupiter, FI 33458, USA. ${ }^{5}$ Present address: Life Sciences Institute, Department of Cell and Developmental Biology, University of Michigan, Ann Arbor, MI 48109, USA

Conflict of interest

The authors declare that they have no conflict of interest.

\section{Publisher's note}

Springer Nature remains neutral with regard to jurisdictional claims in published maps and institutional affiliations.

Supplementary Information accompanies this paper at (https://doi.org/ 10.1038/s41419-019-2135-7).

Received: 29 May 2019 Revised: 5 November 2019 Accepted: 11 November 2019

Published online: 26 November 2019

\section{References}

1. Nieto, M. A. The snail superfamily of zinc-finger transcription factors. Nat. Rev. Mol. Cell Biol. 3, 155-166 (2002).

2. Moody, S. E. et al. The transcriptional repressor snail promotes mammary tumor recurrence. Cancer Cell 8, 197-209 (2005).

3. Wu, Y. \& Zhou, B. P. TNF-alpha/NF-kappaB/Snail pathway in cancer cell migration and invasion. Br. J. Cancer 102, 639-644 (2010).

4. Wang, Y., Shi, J., Chai, K, Ying, X. \& Zhou, B. P. The role of snail in EMT and tumorigenesis. Curr. Cancer Drug Targets 13, 963-972 (2013).

5. Grau, Y., Carteret, C. \& Simpson, P. Mutations and chromosomal rearrangements affecting the expression of snail, a gene involved in embryonic patterning in Drosophila melanogaster. Genetics 108, 347-360 (1984).

6. Nusslein-Volhard, C., Wieschaus, E. \& Kluding, H. Mutations affecting the pattern of the larval cuticle in Drosophila melanogaster. I. Zygotic loci on the second chromosome. Wilehm Roux Arch. Dev. Biol. 193, 267-282 (1984).

7. Leptin, M. twist and snail as positive and negative regulators during Drosophila mesoderm development. Genes Dev. 5, 1568-1576 (1991).

8. Nibu, Y., Zhang, H. \& Levine, M. Interaction of short-range repressors with Drosophila CtBP in the embryo. Science 280, 101-104 (1998). 
9. Nibu, Y. et al. dCtBP mediates transcriptional repression by Knirps, Kruppel and Snail in the Drosophila embryo. EMBO J. 17, 7009-7020 (1998).

10. Weston, C. R. \& Davis, R. J. The JNK signal transduction pathway. Curr. Opin. Cell Biol. 19, 142-149 (2007).

11. Dhanasekaran, D. N. \& Reddy, E. P. JNK signaling in apoptosis. Oncogene 27, 6245-6251 (2008)

12. Igaki, T. \& Miura, M. The Drosophila TNF ortholog Eiger: emerging physiological roles and evolution of the TNF system. Semin. Immunol. 26, 267-274 (2014).

13. Andersen, D. S. et al. The Drosophila TNF receptor Grindelwald couples loss of cell polarity and neoplastic growth. Nature. https://doi.org/10.1038/ nature14298 (2015).

14. Igaki, T. et al. Eiger, a TNF superfamily ligand that triggers the Drosophila JNK pathway. EMBO J. 21, 3009-3018 (2002)

15. Moreno, E., Yan, M. \& Basler, K. Evolution of TNF signaling mechanisms: JNKdependent apoptosis triggered by Eiger, the Drosophila homolog of the TNF superfamily. Curr. Biol. 12, 1263-1268 (2002).

16. Takatsu, Y. et al. TAK1 participates in C-Jun N-terminal kinase signaling during Drosophila development. Mol. Cell Biol. 20, 3015-3026 (2000).

17. Glise, B., Bourbon, H. \& Noselli, S. hemipterous encodes a novel Drosophila MAP kinase kinase, required for epithelial cell sheet movement. Cell $\mathbf{8 3}$, 451-461 (1995).

18. Luo, X., Puig, O., Hyun, J., Bohmann, D. \& Jasper, H. Foxo and Fos regulate the decision between cell death and survival in response to UV irradiation. EMBO J. 26, 380-390 (2007).

19. Accili, D. \& Arden, K. C. FoxOs at the crossroads of cellular metabolism, differentiation, and transformation. Cell 117, 421-426 (2004).

20. Kanda, H., Igaki, T., Okano, H. \& Miura, M. Conserved metabolic energy production pathways govern Eiger/TNF-induced nonapoptotic cell death. Proc. Natl Acad. Sci. USA 108, 18977-18982 (2011).

21. Ma, X. et al. NOPO modulates Egr-induced JNK-independent cell death in Drosophila. Cell Res. 22, 425-431 (2012).

22. Ma, X. et al. Bendless modulates JNK-mediated cell death and migration in Drosophila. Cell Death Differ. 21, 407-415 (2014).

23. Wu, C. et al. Toll pathway modulates TNF-induced JNK-dependent cell death in Drosophila. Open Biol. 5, 140171 (2015).

24. Zhang, S. et al. The canonical Wg signaling modulates Bsk-mediated cell death in Drosophila. Cell Death Dis. 6, e1713 (2015)

25. Abrams, J. M., White, K., Fessler, L. I. \& Steller, H. Programmed cell death during Drosophila embryogenesis. Development 117, 29-43 (1993).

26. Sarkissian, T., Timmons, A., Arya, R., Abdelwahid, E. \& White, K. Detecting apoptosis in Drosophila tissues and cells. Methods 68, 89-96 (2014).

27. Bilen, J. \& Bonini, N. M. Drosophila as a model for human neurodegenerative disease. Annu. Rev. Genet. 39, 153-171 (2005).

28. Lee, T. \& Luo, L. Mosaic analysis with a repressible cell marker for studies of gene function in neuronal morphogenesis. Neuron 22, 451-461 (1999).

29. $\mathrm{Ma}$, X. et al. dUev1a modulates TNF-JNK mediated tumor progression and cell death in Drosophila. Dev. Biol. 380, 211-221 (2013).

30. Alberga, A., Boulay, J. L., Kempe, E., Dennefeld, C. \& Haenlin, M. The snail gene required for mesoderm formation in Drosophila is expressed dynamically in derivatives of all three germ layers. Development 111, 983-992 (1991).

31. Batlle, E. et al. The transcription factor snail is a repressor of E-cadherin gene expression in epithelial tumour cells. Nat. Cell Biol. 2, 84-89 (2000).

32. Cano, A. et al. The transcription factor snail controls epithelial-mesenchyma transitions by repressing E-cadherin expression. Nat. Cell Biol. 2, 76-83 (2000).

33. Ashraf, S. I. \& Ip, Y. T. The Snail protein family regulates neuroblast expression of inscuteable and string, genes involved in asymmetry and cell division in Drosophila. Development 128, 4757-4767 (2001).
34. Cai, Y., Chia, W. \& Yang, X. A family of snail-related zinc finger proteins regulates two distinct and parallel mechanisms that mediate Drosophila neuroblast asymmetric divisions. EMBO J. 20, 1704-1714 (2001).

35. Whiteley, M., Noguchi, P. D., Sensabaugh, S. M., Odenwald, W. F. \& Kassis, J. A The Drosophila gene escargot encodes a zinc finger motif found in snailrelated genes. Mech. Dev. 36, 117-127 (1992).

36. Ashraf, S. I., Hu, X., Roote, J. \& Ip, Y. T. The mesoderm determinant snail collaborates with related zinc-finger proteins to control Drosophila neurogenesis. EMBO J. 18, 6426-6438 (1999).

37. Goyal, L., McCall, K., Agapite, J., Hartwieg, E. \& Steller, H. Induction of apoptosis by Drosophila reaper, hid and grim through inhibition of IAP function. EMBO J. 19, 589-597 (2000).

38. Fan, Y. \& Bergmann, A. The cleaved-Caspase-3 antibody is a marker of Caspase-9-like DRONC activity in Drosophila. Cell Death Differ. 17, 534-539 (2010).

39. Wang, X. et al. FoxO mediates APP-induced AICD-dependent cell death. Cell Death Dis. 5, e1233 (2014)

40. Martin, F. A., Perez-Garijo, A. \& Morata, G. Apoptosis in Drosophila: compensatory proliferation and undead cells. Int. J. Dev. Biol. 53, 1341-1347 (2009).

41. Napoletano, F., Baron, O., Vandenabeele, P., Mollereau, B. \& Fanto, M. Intersections between regulated cell death and autophagy. Trends Cell Biol. 29, 323-338 (2019)

42. Xue, L. et al. Tumor suppressor CYLD regulates JNK-induced cell death in Drosophila. Dev. Cell 13, 446-454 (2007).

43. Martin-Blanco, E et al. puckered encodes a phosphatase that mediates a feedback loop regulating JNK activity during dorsal closure in Drosophila. Genes Dev. 12, 557-570 (1998)

44. Zhang, S. et al. dFoxO promotes Wingless signaling in Drosophila. Sci. Rep. 6 , 22348 (2016).

45. McGill, S., Chia, W., Karp, R. \& Ashburner, M. The molecular analyses of an antimorphic mutation of Drosophila melanogaster, Scutoid. Genetics 119 647-661 (1988).

46. Zhang, $\mathrm{S}$. et al. Wingless modulates activator protein-1-mediated tumor invasion. Oncogene 38, 3871-3885 (2019).

47. Pinal, N., Martin, M., Medina, I. \& Morata, G. Short-term activation of the Jun Nterminal kinase pathway in apoptosis-deficient cells of Drosophila induces tumorigenesis. Nat. Commun. 9, 1541 (2018).

48. Lim, H. Y. \& Tomlinson, A. Organization of the peripheral fly eye: the roles of Snail family transcription factors in peripheral retinal apoptosis. Development 133, 3529-3537 (2006).

49. Bejsovec, A. Flying at the head of the pack: Wnt biology in Drosophila. Oncogene 25, 7442-7449 (2006).

50. Danial, N. N. \& Korsmeyer, S. J. Cell death: critical control points. Cell 116, 205-219 (2004).

51. Hay, B. A., Huh, J. R. \& Guo, M. The genetics of cell death: approaches, insights and opportunities in Drosophila. Nat. Rev. Genet. 5, 911-922 (2004).

52. Nakajima, Y. I. \& Kuranaga, E. Caspase-dependent non-apoptotic processes in development. Cell Death Differ. 24, 1422-1430 (2017).

53. Li, W. Z., Li, S. L., Zheng, H. Y., Zhang, S. P. \& Xue, L. A broad expression profile of the GMR-GAL4 driver in Drosophila melanogaster. Genet. Mol. Res. 11, 1997-2002 (2012)

54. Ma, X. et al. Src42A modulates tumor invasion and cell death via Ben/dUev1amediated JNK activation in Drosophila. Cell Death Dis. 4, e864 (2013).

55. Wang, M. C., Bohmann, D. \& Jasper, H. JNK signaling confers tolerance to oxidative stress and extends lifespan in Drosophila. Dev. Cell 5, 811-816 (2003). 